\title{
ANELAMENTO E REGULADORES DE CRESCIMENTO: EFEITOS SOBRE AS MEDIDAS BIOMÉTRICAS E QUALIDADE DE CACHOS DA VIDEIRA 'SUPERIOR SEEDLESS'
}

\author{
PATRÍCIA COELHO DE SOUZA LEÃO², DAVI JOSÉ SILVA², EMANUEL ÉLDER GOMES DA SILVA
}

\begin{abstract}
RESUMO - Com o objetivo de se obter maior tamanho de baga, peso médio de cacho e produtividade, os cachos da variedade Superior Seedless foram pulverizados com ácido giberélico $\left(1+20 \mathrm{mg} \cdot \mathrm{L}^{-1}\right)$, bioestimulante Crop Set ${ }^{\circledR}$ nas doses de 0,1 e 0,2\% e com ou sem anelamento no caule. Esses tratamentos foram aplicados de forma isolada ou combinados entre si. O trabalho foi conduzido durante o período 2001-2002 (dois ciclos de produção), no Campo Experimental de Bebedouro da Embrapa Semi-Árido em Petrolina-PE. O delineamento experimental foi em blocos ao acaso, com 12 tratamentos e três repetições, sendo duas plantas por parcela. Não foram observadas diferenças significativas entre os tratamentos nos dois ciclos de produção. Entretanto, quando o ácido giberélico foi associado ao Crop Set ${ }^{\circledR}$ 0,1\% e anelamento, observou-se uma tendência de aumento no peso de cachos, bem como no peso e tamanho de bagas na safra de 2001. Os cachos tratados com ácido giberélico apresentaram engaços mais grossos e pesados, embora não se observem diferenças significativas entre os tratamentos. Algumas plantas submetidas ao anelamento apresentaram problemas de cicatrização, o que provocou a morte das mesmas, recomendando-se evitar a realização desta prática nas condições em que se realizou este trabalho.
\end{abstract}

Termos para indexação: uvas sem sementes, bioestimulante, ácido giberélico, Crop Set ${ }^{\circledR}$

\section{GIRDLING AND GROWTH REGULATORS: EFFECTS ON THE BIOMETRIC MEASUREMENTS AND QUALITY OF BUNCHES OF VINE 'SUPERIOR SEDLESS'}

\begin{abstract}
Aiming to increase the berry size, weight of bunches and yield, the bunches of the cv. Superior Seedless was powdered with gibberelic $\operatorname{acid}\left(1+20 \mathrm{mg} . \mathrm{L}^{-1}\right)$, bio-stimulant Crop Set ${ }^{\circledR}$ in the dosis of 0.1 and $0.2 \%$. In adition was used the treatment known as girdling. Those treatments were applied in an isolated way or combined to each other. The work was carried out during 2001-2002 (two harvest seasons), in the Experimental Station of Bebedouro, Semi-arid Embrapa in Petrolina, Pernambuco State. The experimental design were in randomized blocks with 12 treatments and three replications. The differences among the treatments were not statistical significant in the two evaluated seasons. However, when the gibberelic acid was associated with Crop Set巴 $0.1 \%$ and girdling, it was observed a tendency to increase the weight of bunches, as well as, the weight and berry size in the 2001 season. The bunches treated with gibberelic acid presented stronger rachis, although significant differences are not observed among the treatments. Some plants submited to the girdling presented problems with cicatrization, that caused death of them, recomending to avoid this practice in the conditions of this work.
\end{abstract}

Index terms: seedless grapes, bio-stimulant, gibberelic acid, Crop Set ${ }^{\circledR}$

\section{INTRODUÇÃO}

O Vale do São Francisco é a principal região produtora de uvas sem sementes do País. Nos últimos anos, esta região apresentou uma grande expansão da produção, estimando-se atualmente uma área colhida superior a 2.000 ha. 'Superior Seedless' ou 'Festival' é a principal variedade de uvas sem sementes e pode, de acordo com o manejo, apresentar cachos e bagas grandes. A aparência dos cachos e o tamanho das bagas podem ser melhorados com a utilização de reguladores de crescimento, bioestimulantes e a técnica denominada de anelamento (Winkler, 1970; Cirami, 1992).

O ácido giberélico aplicado após o pegamento dos frutos promove aumento no tamanho de bagas, principalmente de uvas sem sementes. No Chile, Muñoz \& Pezoa (1993) observaram, na variedade Superior Seedless, que a combinação de ácido giberélico e anelamento promoveu maior produção, peso de cachos, peso dos engaços e diâmetro de bagas. No Brasil, resultados semelhantes foram obtidos em outras variedades por diversos autores (Castro et al., 1974; Pereira \& Oliveira, 1976; Pereira et al., 1979; Guerra et al., 1981; Maraschin et al., 1986; Pires et al., 1986; Pommer et al., 1995).

O uso de citocininas na viticultura é recente, não sendo ainda largamente utilizadas como as giberelinas e auxinas. Desde sua descoberta na década de cinqüenta como hormônios relacionados à divisão celular, tem sido mostrado que as citocininas também estão envolvidas na diferenciação, alongamento celular, crescimento e senescência foliar, dominância apical, germinação, desenvolvimento de organelas, atividade enzimática, abertura estomática, desenvolvimento de frutos e hidrólise de reservas de sementes
(Davies, 1988). O CPPU [N-(2-cloro-piridil)-N-fenilúreia ou forchlorofenuron] é reconhecido por ser uma citocinina mais potente que aquelas derivadas da adenina (Nickel, 1986). No Vale do São Francisco, o maior tamanho de bagas e peso de cachos foram obtidos nas variedades Perlette e Superior Seedless quando o ácido giberélico e o CPPU foram associados (Leão et al., 1999; Mashima et al., 1999).

Atualmente, a utilização do CPPU não é permitida em muitos países, além de não ser um produto registrado no Brasil, o que tem levado à utilização de produtos naturais que contenham citocinina. Alguns extratos naturais são ricos em citocininas e apresentam atividade típica de divisão celular. Segundo Metivier (1979) e Taiz \& Zeiger (1991), níveis altos de citocininas, normalmente, são encontrados em meristemas com alta taxa de divisão celular.

O produto comercial Crop Set ${ }^{\circledR}$ encontra-se registrado no Brasil como fertilizante foliar composto por 1,5\% de manganês, $1,5 \%$ de ferro e $1 \%$ de cobre, e as informações do fabricante indicam que o mesmo é um estimulante vegetal composto de extratos de agave com ação semelhante às citocininas.

O anelamento é realizado em uvas sem sementes para aumentar o tamanho de bagas, sobretudo como uma prática complementar à aplicação do ácido giberélico (Winkler, 1970). Entretanto, o anelamento realizado sucessivamente após vários anos poderá reduzir o tamanho dos cachos e a vida útil das plantas (Cirami et al., 1992).

O objetivo do presente trabalho foi avaliar os efeitos da utilização do ácido giberélico, Crop Set ${ }^{\circledR}$ e anelamento isolados ou combinados entre si, sobre a qualidade dos cachos da variedade Superior Seedless, no Vale do São Francisco.

\footnotetext{
${ }^{1}$ (Trabalho 085/2004). Recebido: 08/06/2004. Aceito para publicação: 06/12/2004.

${ }^{2}$ Pesquisadores Embrapa Semi-Árido, BR 428, Cx.Postal 23, Petrolina-PE, CEP.56.302-970, patricia@ cpatsa.embrapa.br, davi@cpatsa.embrapa.br.

${ }^{3}$ Bolsista CNPq.
} 


\section{MATERIALEMÉTODOS}

O experimento foi realizado, durante dois ciclos de produção, em um vinhedo da variedade Superior Seedless (Festival), localizado no Campo Experimental de Bebedouro e pertencente à Embrapa Semi-Árido, em Petrolina-PE. As datas de colheita foram, respectivamente, 30-072001 para o $1^{\circ}$ ciclo de produção e $15-07-2002$ para o $2^{\circ}$ ciclo de produção. O clima da região é classificado, segundo Köeppen, como tipo Bswh, que corresponde a uma região Semi-Árida muito quente. $\mathrm{O}$ índice pluviométrico anual é de $571,5 \mathrm{~mm}$. A temperatura média anual é de $26,4^{\circ} \mathrm{C}$, com média das mínimas de $20,6^{\circ} \mathrm{C}$, e média das máximas $31,7^{\circ} \mathrm{C}$.

As plantas da área experimental foram conduzidas em latada sob irrigação por gotejamento, no espaçamento 4,0 x 2,0m. As podas foram do tipo mista com varas e esporões nos dois ciclos de produção, com comprimento médio da poda em torno de 10 gemas. Os demais tratos culturais foram aqueles recomendados para o sistema de produção de uvas de mesa no Vale do São Francisco.

O delineamento utilizado foi o de blocos casualizados, com três repetições e duas plantas úteis por parcela. Os tratamentos foram os seguintes: 1) Testemunha; 2) Anelamento (A); 3) Ácido giberélico (AG3); 4) Crop Set ${ }^{\circledR}(\mathrm{CS}) 0,1 \%$; 5) $\operatorname{Crop} \operatorname{Set}{ }^{\circledR}(\mathrm{CS}) 0,2 \%$; 6) Anelamento + Crop Set ${ }^{\circ} 0,1 \%$; 7) Anelamento + Crop Set ${ }^{\circledR} 0,2 \%$; 8) Anelamento + Ácido giberélico; 9) Ácido giberélico + Crop Set ${ }^{\circledR} 0,1 \%$; 10) Ácido giberélico + Crop Set ${ }^{\circledR} 0,2 \%$; 11) Anelamento + Ácido giberélico + Crop Set ${ }^{\circledR} 0,1 \%$ e 12) Anelamento + Ácido giberélico + Crop $\operatorname{Set}{ }^{\circledR} 0,2 \%$. O anelamento foi realizado quando as bagas apresentavam entre 8 a $9 \mathrm{~mm}$ de diâmetro, efetuando-se um corte de cerca de 4 a $5 \mathrm{~mm}$ de largura no caule das plantas acerca de $1,0 \mathrm{~m}$ de altura do solo, utilizando-se de incisor com faca dupla. $\mathrm{O}$ ácido giberélico foi aplicado em duas fases: $1 \mathrm{mg} . \mathrm{L}^{-1}$ quando os cachos tinham cerca de $2 \mathrm{~cm}$ de comprimento e $20 \mathrm{mg} . \mathrm{L}^{-1}$ na fase de 'chumbinho' (bagas com 4 a 6 mm de diâmetro), através de pulverização dirigida aos cachos. O Crop Set ${ }^{\circledR}$ foi aplicado 7 dias após a aplicação do ácido giberélico ( 8 a $9 \mathrm{~mm}$ de diâmetro de bagas).

Foram avaliadas as seguintes variáveis: produção $(\mathrm{t} / \mathrm{ha})$, peso de cacho $(\mathrm{g})$, peso $(\mathrm{g})$, comprimento $(\mathrm{mm})$ e diâmetro de baga $(\mathrm{mm})$, peso do engaço $(\mathrm{g})$, desgrane de bagas, sólidos solúveis totais ( $\left.{ }^{\circ} \mathrm{Brix}\right)$, acidez total titulável (\% de ácido tartárico) e relação SST/ATT.

Foram amostrados 5 cachos de cada planta útil e retirando-se dez bagas de cada um deles, formando uma amostra de 50 bagas por planta, onde foram medidos peso, comprimento e diâmetro, utilizandose desta mesma amostra para a extração do suco e determinação dos teores de SST através de leitura em refratômetro digital e ATT através de titulação com NaOH 0,1N (IAL, 1985). Determinou-se o peso fresco (g) do engaço dos cinco cachos.
A análise estatística dos dados obtidos consistiu na análise de variância e a comparação entre médias pelo teste de Tukey $(\mathrm{p}<0,05)$, utilizando-se do programa SAS (1989).

\section{RESULTADOSE DISCUSSÃO}

Os resultados obtidos no $1^{\circ}$ ciclo de produção são apresentados na Tabela 1. Nesta Tabela, observa-se que não houve efeitos significativos dos tratamentos sobre o tamanho e o peso de cachos e bagas, na produtividade e no teor de sólidos solúveis totais e acidez total titulável dos frutos. Entretanto, observou-se uma tendência de maior peso de cachos e tamanho de bagas no tratamento combinado de anelamento, ácido giberélico e Crop Set ${ }^{\circledR} \quad 0,1 \%$, com aumentos percentuais de $17 \%$ sobre o peso de bagas e $9 \%$ sobre o comprimento e diâmetro de bagas. A produtividade não foi influenciada pelos tratamentos, obtendo-se uma média de 44 cachos por planta e aproximadamente $12 \mathrm{t} / \mathrm{ha}$. O teor de sólidos solúveis totais (SST) dos frutos variou de $15,80 \mathrm{a} 16,90^{\circ} \mathrm{Brix}$, enquanto a acidez total titulável (ATT) variou de 0,60 a $0,70 \%$, correspondendo a uma relação SST/ATT acima de 22. Os cachos tratados com ácido giberélico apresentaram engaços mais grossos e com maior diâmetro, resultando em diferenças significativas no peso dos engaços entre os tratamentos anelamento + ácido giberélico + Crop Set 0,2\% e Crop Set 0,2\%. O aumento na espessura de engaços e pedicelos pode aumentar de desgrane de bagas na fase de pós-colheita, prejudicando ainda a formação e a aparência do cacho. Contudo, estes efeitos negativos não foram observados neste trabalho.

No $2^{\circ}$ ciclo avaliado, foram confirmados os resultados obtidos no ciclo anterior, ou seja, não significância nos valores das características estudadas. Não foram observados efeitos do ácido giberélico, do anelamento e do bioestimulante Crop Set sobre o aumento do tamanho de bagas e cachos, bem como na produtividade da variedade Superior Seedless (Tabela 2). Estes resultados diferem daqueles obtidos no Chile com a mesma variedade, utilizando-se da mesma concentração de ácido giberélico (20 ppm) e anelamento para crescimento de bagas (Muñoz \& Pezoa, 1993). No entanto, a resposta obtida em relação à citocinina estão de acordo com Lacobelli (1995), que não encontraram efeitos positivos sobre a melhoria na qualidade dos cachos da uva 'Superior Seedless' tratados com CPPU.

As bagas apresentaram comprimento máximo de 23,06 mm e 19,36 mm de diâmetro, o que é considerado um tamanho de bagas pequeno para esta variedade, onde podem ser obtidas bagas com $24 \mathrm{~mm}$ de diâmetro quando tratadas com ácido giberélico, CPPU e anelamento (Mashima et al., 1999). A produtividade média dos tratamentos foi de $6 \mathrm{t} /$

TABELA 1 - Efeitos do ácido giberélico (AG3), anelamento (A) e Crop Set ${ }^{\circledR}$ (CS) sobre a qualidade de cachos da uva ‘Superior Seedless', PetrolinaPE, 2001.

\begin{tabular}{|c|c|c|c|c|c|c|c|c|c|c|}
\hline TRATAMENTOS & $\begin{array}{c}\text { Peso } \\
\text { de cachos } \\
(\mathrm{g})\end{array}$ & $\begin{array}{c}\text { Peso } \\
\text { de bagas } \\
\text { (g) }\end{array}$ & $\begin{array}{l}\text { Comprimento } \\
\text { de bagas } \\
(\mathrm{mm})\end{array}$ & $\begin{array}{c}\text { Diâmetro } \\
\text { de bagas } \\
(\mathrm{mm})\end{array}$ & $\begin{array}{l}\text { Peso do } \\
\text { engaço } \\
(\mathrm{g})\end{array}$ & $\begin{array}{l}\text { Produçã } \\
\text { o (t/ha) }\end{array}$ & $\begin{array}{l}\mathrm{N}^{\circ} \text { de } \\
\text { cachos }\end{array}$ & $\begin{array}{c}\text { SST } \\
\left({ }^{\circ} \text { Brix }\right)\end{array}$ & $\begin{array}{c}\text { ATT } \\
(\% \\
\text { ác.tart. })\end{array}$ & $\begin{array}{c}\text { Relação } \\
\text { SST/AT } \\
\mathrm{T}\end{array}$ \\
\hline $\mathrm{T}$ & 280,97 & 5,24 & 23,03 & 19,33 & $6,90 \mathrm{ab}$ & 11,54 & 42 & 15,97 & 0,67 & 23,97 \\
\hline A & 295,92 & 5,78 & 24,13 & 20,27 & $6,63 \mathrm{ab}$ & 10,67 & 36 & 16,63 & 0,65 & 26,63 \\
\hline AG3 & 285,96 & 5,59 & 23,90 & 20,33 & $10,57 \mathrm{ab}$ & 14,17 & 51 & 16,17 & 0,65 & 25,03 \\
\hline $\mathrm{CS} 0,1 \%$ & 257,63 & 5,36 & 23,50 & 19,50 & $6,67 \mathrm{ab}$ & 11,21 & 47 & 16,67 & 0,69 & 24,13 \\
\hline $\operatorname{CS} 0,2 \%$ & 305,06 & 5,20 & 23,03 & 19,57 & $5,97 \quad b$ & 12,33 & 44 & 16,03 & 0,65 & 24,83 \\
\hline$A+C S 0,1 \%$ & 288,26 & 5,45 & 23,01 & 20,10 & $7,43 \mathrm{ab}$ & 14,25 & 48 & 17,53 & 0,70 & 24,97 \\
\hline$A+C S 0,2 \%$ & 271,39 & 5,58 & 23,70 & 20,10 & $6,07 \mathrm{ab}$ & 13,04 & 49 & 16,47 & 0,60 & 27,47 \\
\hline $\mathrm{A}+\mathrm{AG} 3$ & 295,62 & 6,10 & 25,10 & 20,40 & $10,63 \mathrm{ab}$ & 13,75 & 50 & 16,73 & 0,76 & 22,30 \\
\hline$A+\operatorname{CS} 0,1 \%$ & 267,27 & 5,51 & 23,70 & 20,03 & $10,50 \mathrm{ab}$ & 11,25 & 38 & 16,90 & 0,73 & 23,33 \\
\hline $\mathrm{AG} 3+\mathrm{CS} 0,2 \%$ & 283,35 & 5,27 & 23,87 & 19,27 & $10,67 \mathrm{ab}$ & 7,95 & 40 & 16,80 & 0,63 & 26,50 \\
\hline $\mathrm{A}+\mathrm{AG} 3+\mathrm{CS} 0,1 \%$ & 334,04 & 6,26 & 25,30 & 21,23 & $13,50 \mathrm{a}$ & 11,04 & 36 & 15,80 & 0,68 & 23,37 \\
\hline $\mathrm{A}+\mathrm{AG} 3+\mathrm{CS} 0,2 \%$ & 279,73 & 5,70 & 24,37 & 19,80 & $9,77 \mathrm{ab}$ & 10,17 & 44 & 16,57 & 0,70 & 23,77 \\
\hline Média & 287,10 & $\mathbf{5 , 5 9}$ & 23,89 & 20,00 & 8,78 & 11,78 & 44 & 16,52 & 0,68 & 24,69 \\
\hline $\operatorname{Pr}>F$ & $0,93 \mathrm{~ns}$ & $0,37 \mathrm{~ns}$ & $0,15 \mathrm{~ns}$ & $0,27 \mathrm{~ns}$ & 0,02 & $0,32 \mathrm{~ns}$ & $0,13 \mathrm{~ns}$ & $0,12 \mathrm{~ns}$ & $0,45 \mathrm{~ns}$ & $0,46 \mathrm{~ns}$ \\
\hline C. V. (\%) & 18,51 & 9,59 & 4,20 & 4,12 & 28,67 & 24,25 & 16,64 & 3,76 & 10,97 & 10,63 \\
\hline
\end{tabular}

Médias seguidas pela mesma letra na coluna não diferem entre si, pelo teste Tukey, a $\%$ de probabilidade 
TABELA 2 - Efeitos do ácido giberélico (AG3), anelamento (A) e Crop Set ${ }^{\circledR}$ (CS) sobre a qualidade de cachos da uva 'Superior Seedless', PetrolinaPE, 2002.

\begin{tabular}{|c|c|c|c|c|c|c|c|c|c|c|}
\hline TRATAMENTOS & $\begin{array}{c}\text { Peso } \\
\text { de cachos } \\
(\mathrm{g})\end{array}$ & $\begin{array}{c}\text { Peso } \\
\text { de bagas } \\
(\mathrm{g})\end{array}$ & $\begin{array}{c}\text { Comprimento } \\
\text { de bagas } \\
(\mathrm{mm})\end{array}$ & $\begin{array}{l}\text { Diâmetro } \\
\text { de bagas } \\
(\mathrm{mm})\end{array}$ & $\begin{array}{l}\text { Peso do } \\
\text { engaço } \\
(\mathrm{g})\end{array}$ & $\begin{array}{c}\text { Produçã } \\
\text { o (t/ha) }\end{array}$ & $\begin{array}{l}\mathrm{N}^{\circ} \text { de } \\
\text { cachos }\end{array}$ & $\begin{array}{c}\text { SST } \\
\left({ }^{\circ} \text { Brix }\right)\end{array}$ & $\begin{array}{c}\text { ATT } \\
(\% \\
\text { ác.tart. })\end{array}$ & $\begin{array}{c}\text { Relação } \\
\text { SST/AT } \\
\text { T }\end{array}$ \\
\hline $\mathrm{T}$ & 221,68 & 4,89 & 22,50 & 19,13 & 5,44 & 4,79 & 23 & $16,33 \mathrm{a}$ & 0,78 & 21,21 \\
\hline A & 270,60 & 5,33 & 23,00 & 19,36 & 5,76 & 7,50 & 27 & $15,86 \mathrm{ab}$ & 0,82 & 19,44 \\
\hline AG3 & 220,02 & 4,75 & 22,46 & 18,76 & 7,76 & 8,33 & 34 & $15,66 \mathrm{ab}$ & 0,76 & 20,66 \\
\hline $\mathrm{CS} 0,1 \%$ & 235,29 & 4,76 & 22,56 & 18,96 & 5,50 & 4,54 & 22 & $16,40 \mathrm{a}$ & 0,85 & 19,39 \\
\hline CS $0,2 \%$ & 227,86 & 4,37 & 21,76 & 18,46 & 5,46 & 6,50 & 27 & $16,40 \mathrm{a}$ & 0,74 & 22,23 \\
\hline $\mathrm{A}+\mathrm{CS} 0,1 \%$ & 188,70 & 4,62 & 22,00 & 18,90 & 5,51 & 6,79 & 31 & $16,90 \mathrm{a}$ & 0,80 & 21,15 \\
\hline$A+\operatorname{CS} 0,2 \%$ & 209,59 & 4,11 & 20,93 & 18,13 & 4,67 & 5,70 & 26 & $16,50 \mathrm{a}$ & 0,78 & 21,47 \\
\hline $\mathrm{A}+\mathrm{AG} 3$ & 275,71 & 4,00 & 20,70 & 18,33 & 8,19 & 7,66 & 30 & $14,30 \mathrm{~b}$ & 0,79 & 18,05 \\
\hline $\mathrm{AG} 3+\mathrm{CS} 0,1 \%$ & 192,96 & 4,78 & 22,60 & 18,73 & 6,69 & 5,41 & 25 & $16,10 \mathrm{a}$ & 0,80 & 20,13 \\
\hline $\mathrm{AG} 3+\mathrm{CS} 0,2 \%$ & 198,55 & 4,95 & 22,93 & 18,96 & 6,10 & 5,08 & 26 & $16,03 \mathrm{ab}$ & 0,78 & 20,42 \\
\hline $\mathrm{A}+\mathrm{AG} 3+\mathrm{CS} 0,1 \%$ & 241,35 & 4,98 & 22,70 & 19,20 & 7,18 & 8,79 & 34 & $15,83 \mathrm{ab}$ & 0,75 & 21,28 \\
\hline $\mathrm{A}+\mathrm{AG} 3+\mathrm{CS} 0,2 \%$ & 169,49 & 4,55 & 23,06 & 19,00 & 6,97 & 4,58 & 24 & $16,36 \mathrm{a}$ & 0,74 & 22,02 \\
\hline Média & 220,98 & 4,68 & 22,27 & 18,83 & 6,27 & 6,30 & 28 & 16,05 & $\mathbf{0 , 7 8}$ & 20,62 \\
\hline $\operatorname{Pr}>\mathrm{F}$ & $0,25 \mathrm{~ns}$ & $0,15 \mathrm{~ns}$ & $0,08 \mathrm{~ns}$ & $0,52 \mathrm{~ns}$ & $0,11 \mathrm{~ns}$ & $0,43 \mathrm{~ns}$ & $0,80 \mathrm{~ns}$ & 0,005 & $0,81 \mathrm{~ns}$ & $0,42 \mathrm{~ns}$ \\
\hline C. V. $(\%)$ & 21,24 & 10,79 & 4,31 & 3,45 & 21,94 & 39,96 & 32,47 & 3,72 & 9,43 & 9,8 \\
\hline
\end{tabular}

Médias seguidas pela mesma letra na coluna não diferem entre si, pelo teste Tukey, a $5 \%$ de probabilidade

ha, ou seja, muito baixa, possivelmente devido a aspectos do manejo, como tipo de poda e porta-enxerto utilizados, os quais não foram os mais adequados para a variedade. Os engaços dos cachos onde se aplicou o ácido giberélico, demonstrou tendência de maior peso que os demais tratamentos, embora não tenham sido observadas diferenças significativas entre eles (Tabelas 1 e 2). Essa característica resultou em aumento na espessura e no diâmetro do engaço e dos pedicelos, o que tem como conseqüência o aumento do desgrane das bagas na colheita e pós-colheita, e está de acordo com os resultados obtidos por outros autores em diferentes variedades de uvas de mesa (Muñoz \& Pezoa, 1993; Retamales \& Cooper, 1993; Cooper et al., 1993). Segundo Pérez \& Morales (1999), o ácido giberélico, em doses crescentes, aumentou a atividade da peroxidase solúvel dos pedicelos de uva 'Sultana', sugerindo que estas enzimas estão envolvidas na lignificação de pedicelos e engaços, levando à perda de flexibilidade e ao desgrane de bagas na pós-colheita.

Embora tenham sido observadas diferenças entre o teor de sólidos solúveis totais de alguns tratamentos, não são evidentes os efeitos do ácido giberélico, anelamento e Crop Set ${ }^{\circledR}$ sobre esta característica. A acidez total titulável não foi influenciada pelos tratamentos, variando de 0,74 a $0,85 \%$. Por sua vez, a relação SST/ATT, embora tenha sido pouco inferior ao $1^{\circ}$ ciclo, esteve em torno de 20 , que é recomendada para comercialização de uvas de mesa. Estes resultados diferem daqueles obtidos por outros autores que observaram que o ácido giberélico e a citocinina causaram redução do teor de sólidos solúveis totais, retardando a colheita (Ben Tal, 1990; Retamales et al., 1995; Joublan et al., 1995; Leão et al., 1999).

O caule de algumas plantas aneladas não cicatrizou completamente, causando a interrupção do fluxo da seiva, o que levou à morte de plantas. Esta prática constitui-se ainda num fator de estresse para a planta e porta de entrada para patógenos e, portanto, deve ser realizada com muita cautela.

\section{CONCLUSÕES}

Nas condições em que este trabalho foi realizado:

1. Não se observam efeitos do ácido giberélico, Crop Set ${ }^{\circledR}$ e anelamento, isolados ou combinados entre si sobre o aumento do tamanho de cachos, bagas e produção nos dois ciclos de produção estudados.

2. Os engaços dos cachos tratados com ácido giberélico apresentam tendência de maior peso, o que não chegou a prejudicar a formação e a aparência dos cachos.

3. O teor de sólidos solúveis totais apresentou diferenças entre os tratamentos apenas no $2^{\circ}$ ciclo (2002), embora não tenham sido observados efeitos sobre a acidez total e relação SST/ATT dos frutos.

4. O anelamento não cicatrizou totalmente, provocando a morte de plantas, recomendando-se que esta prática seja realizada com cautela no Vale do São Francisco.

\section{AGRADECIMENTOS}

Ao Banco do Nordeste do Brasil (Fundeci/Etene) e Improcrop, pelo apoio financeiro para a realização dos trabalhos

\section{REFERÊNCIAS}

BEN TAL, Y. Effects of gibberellin treatments on ripening and berry drop from Thompson Seedless grapes. American Journal of Enology and Viticulture, v.41, n.2, 1990.

CASTRO, P. R. C.; FERRAZ, E. C.; SCARANARI, H. J. Efeitos de giberelinas e auxina na frutificação da videira 'Niágara Rosada'. In: E.S.A. "Luiz de Queiroz”. Anais... v.31, p.367-383, 1974.

CIRAMI, R. M.; CAMERON, I. J.; HEDBERG, P. R. Special Cultural Methods for tablegrapes. In: Viticulture, v.2, Coombe, B. G.; Dry, P. R. Ed. Winetitles, Adelaide, 1992, p.279-301.

COOPER, T.; RETAMALES, J.; BANGERTH, F. Berry drop occurence as affected by GA3 and promalin applications in Thompson Seedless grapes. Acta Horticulturae, n.329, p.134-136, 1993.

DAVIES, P. J. The plant hormones: their nature, ocurrence, and functions. In: Plant hormones and their role in plant growth and development. 2ed. Dordrecht: Kluwer Academic Publishers, p.1-11, 1988.

GUERRA, M.P.; BARCELLOS, F. M.; KOLLER, O. C. Influência do ácido giberélico, aplicado em floração e pós-floração sobre as características do cacho da videira Itália ( V. vinifera L.). In: CONGRESSOBRASILEIRODEFRUTICULTURA, 6, Recife-PE, 1981. Anais... Sociedade Brasileira de Fruticultura, Recife-PE, v.4, p.12781286, 1981.

JOUBLAN, J.; MERINO, R.; WILCKENS, E.; MEDINA, E. Efecto del CPPU y ácido giberélico en frutos de vid cv. Moscatel Rosada. Agro-Ciencia, v.11, n.2, p.119-127, 1995.

LACOBELLI, F. Efecto del forchlorfenuron (CPPU) sobre el crecimiento de las bayas y la calidad de las uvas en los cv. Superior Seedless y Red Globe. Santiago, Chile, 1995. 38 p. 1995. Dissertação (Graduação em Agronomia), Universidade Católica do Chile, Faculdade de Agronomia. Santiago, Chile.

LEÃO, P.C.S.; LINO JUNIOR, E. C.; SANTOS, E. S. Efeitos do CPPU e ácido giberélico sobre o tamanho de bagas da uva Perlette cultivada 
no Vale do São Francisco. Revista Brasileira de Fruticultura, v.21, n.1, p.74-78, 1999.

MARASCHIN, M.; GUERRA, M. P.; SILVA, A. L. Efeitos do ácido giberélico ethephon sobre as características dos cachos e frutos da cv. Niágara Branca (Vitis labrusca L.). Revista Brasileira de Fruticultura, v.8, n.2, p.51-57, 1986.

MASHIMA, C. H.; FEITOSA, C. A. M.; LOPES, A. M. S. Efeitos de CPPU, AG3 e anelamento em uva apirênica 'Festival' no Vale do Submédio São Francisco. In: CONGRESSO BRASILEIRO DE VITICULTURA E ENOLOGIA, IX, Bento Gonçalves, RS. Anais.... Embrapa Uva e Vinho, dezembro de 1999, p.141.

METIVIER. Citocininas In: Ferri, M.G. Fisiologia vegetal 2. São Paulo, EDUSP.p. 90-127.1979.

MUÑOZ, I; PEZOA, J. Cultivar Superior: acción del ácido giberélico y annilado. Investigación y Progreso Agropecuario, La Platina n ${ }^{\circ} 79$, p.18-20, 1993.

NICKEL, L.G. The effects of N-(2-chloro-4-pyridyl)-N-phenylurea and 3chloro-benzyl ester of dicamba on the growth and sugar content of grapes. Acta Horticulturae, n. 179, p.805-806,1986.

PEREIRA, F. M.; OLIVEIRA, J.C. Ação da giberelina sobre cachos da cultivar de videira Patrícia. Científica, v.4, n.2, p.175-180, 1976.

PEREIRA, F. M.; SIMÃO, S.; MARTINS, F. P.; IGUE, T. Efeitos da giberelina sobre cachos da cultivar de videira Niagara Rosada. Científica, v.7, n.1, p.53-58, 1979.
PÉREZ, F. J.; MORALES, V. A basic peroxidase isoenzyme from the grape pedicel is induced by gibberelic acid. Australian Journal of Plant Physiology, v.26, p.387-390, 1999.

PIRES, E. J. P; FAHL, J. I.; CARELLI, M. L. C.; TERRA, M. M.; PASSOS, I. R. S.; CRUZ, L. S. P.; MARTINS, F. P. Respostas à aplicação de ácido giberélico (GA) em panículas de videira da cultivar IAC 871-13 ADona. In: CONGRESSO BRASILEIRO DE FRUTICULTURA, 8, Brasília, 1986. Anais... Brasília:Embrapa DDT/CNPq, v.2, p.473-477, 1986.

POMMER, C. V.; TERRA, M. M.; PIRES, E. J.P.; PICININ,A. H.; PASSOS, I. R. S. Influência do anelamento e do ácido giberélico em características da cultivar apireno de uvas Maria. Bragantia, v.54, n.1, p.151-159, 1995.

RETAMALES, J.; BANGERTH, F.; COOPER, T.; CALLEJAS, R. Effects of CPPU and GA3 on fruit quality of Sultanina table grape. Acta Horticulturae, n.394,p.149-157, 1995.

RETAMALES, J.; COOPER, T. Berry drop and fruit removal forces as related with GA3 applications in table grapes. Acta Horticulturae, n.329, p.81-83, 1993.

TAIZ, L; ZEIGER. Plant Physiology. Redwood City, Benjamin/Cummings P. Co. 559p. 1991.

WINKLER, J. A. General viticulture. University of California. Press. Beckeley, Los Angeles, 1970. 